\title{
Using Interpretive Qualitative Case Studies for Exploratory Research in Doctoral Studies: A Case of Information Systems Research in Small and Medium Enterprises
}

\author{
Shana R. Ponelis \\ University of Wisconsin-Milwaukee, Milwaukee, WI, USA \\ ponelis@uwm.edu
}

\begin{abstract}
The use of the case study method has gained mainstream acceptance in both entrepreneurship and information systems research to develop conceptual and theoretical models that are novel, yet grounded in the literature. In spite of many texts on the case study method and the growing acceptance and use of thereof, there are relatively few examples that discuss how to apply the case study method. The purpose of this paper is to provide such an example by drawing upon the author's research for her doctoral dissertation in the discipline of information systems and entrepreneurship research. First, the use of qualitative case studies as research method is motivated, then the importance of the research paradigm is discussed and the interpretivist research paradigm justified followed by a detailed discussion of the research design. The paper concludes with a discussion of lessons learned and recommendations based on the author's experience with using the case study method. The practical yet theoretically founded approach of this paper may be useful to doctoral students who are considering or using the case study method. Equally, supervisors and others involved in research training may find this paper useful as an illustrative example of the case study method for their students.
\end{abstract}

Keywords: case study method, qualitative methods, interpretive research paradigm, exploratory research, theory building, semi-structured interviews, information systems, IS, entrepreneurship, small and medium enterprises, SMEs.

\section{Introduction}

The case study method can be used as both a teaching method and a research strategy. As a teaching method it simulates real-life situations in the classroom for discussion and debate or for casebased assignments. As a research strategy case studies are used in a variety of contexts and disci-

Material published as part of this publication, either on-line or in print, is copyrighted by the Informing Science Institute. Permission to make digital or paper copy of part or all of these works for personal or classroom use is granted without fee provided that the copies are not made or distributed for profit or commercial advantage AND that copies 1) bear this notice in full and 2) give the full citation on the first page. It is permissible to abstract these works so long as credit is given. To copy in all other cases or to republish or to post on a server or to redistribute to lists requires specific permission and payment of a fee. Contact Publisher@InformingScience.org to request redistribution permission. plines, for example, in organizations in marketing and information systems (IS); in small communities, households, families in psychology and social work; or in countries, nations or regions in political science (Davies, 2007; Mouton, 2001). The purpose of such case studies is to provide an intensive, holistic description and analysis of a single, bounded unit situated in a specific context to provide insight into real-life situ- 
ations (Merriam, 2009; Pickard, 2013). The case study method is a popular research method that is particularly appealing for applied disciplines since processes, problems, and/or programs can be studied to engender understanding that can improve practice. Using a case study approach in research has several strengths including the ability to use a variety of research methods (Davies, 2007), the ability to establish rapport with research subjects (Mouton, 2001), to obtain sufficiently rich description that can be transferred to similar situations (Merriam, 2009) and, ultimately, indepth insight.

In spite of, or perhaps because of, the popularity and the multitude of publications on the case study method this author struggled to translate the theory to practice in her doctoral research, an experience that is not uncommon amongst doctoral students who want specific examples of "how to do it" (Walsham, 2006, p. 321). This paper aims to provide a specific example for doctoral researchers that illustrates how to provide adequate philosophical grounding and theoretical justification for using case studies as research method by drawing upon the author's doctoral dissertation reporting on an exploratory study of an emerging technology, business intelligence, to meet information needs and support decision-making in small and medium enterprises in South Africa (Ponelis, 2011). The next section provides a brief overview of the research project in order to contextualize the discussion in the subsequent sections. Thereafter the importance and choice of a research paradigm is discussed as well as the criteria used for assessing research. This section is followed by the rationale for using the case study method within the chosen paradigm. Thereafter the research design is explained and the paper concludes with lessons learned and recommendations with respect to the use of case studies as a research method.

\section{The Project}

It is vital for SMEs to take a strategic approach to their information needs if they wish to develop and remain competitive (Sen \& Taylor, 2007). Without accurate information SMEs will struggle to make operational, tactical, and strategic decisions (Maguire, Koh, \& Magrys, 2007). The ability to utilize information technology (IT) to inform decision-making is a key influence upon the competitiveness of small and medium enterprises (SMEs) (Levy \& Powell, 2005).

SMEs tend to spend their available resources on operational systems when it comes to IT. But these systems, whilst necessary, are not sufficient. They are geared toward capturing data but not producing information. Business intelligence (BI), an emerging technology for SMEs, can provide decision-makers, who in SMEs are predominantly the owner/managers, with interactive access to integrated, primarily internal data that enables them to make informed decisions on where to apply their limited resources. Because BI requires operational systems to be in place to gather data it is the logical next step in terms of IT investment. Despite increasing discussion in the press and amongst BI practitioners, academic research with regard to BI in SMEs was sparse at the time, particularly in South Africa.

Since the potential contribution of BI to SMEs can be assessed only by first understanding existing information needs and practices from the perspective of the key SME decision-maker, the owner/manager(s), the purpose of this study was to explore and understand the use of information and BI, if any, to support strategic, tactical, and operational decision-making in South African SMEs.

\section{The Research Method}

Emerging technologies researchers usually have an exploratory and applied focus (Barnes, Buckland, \& Brancheau, 1992). This focus increases the relevance of research results for stakeholders but care must be taken not to pay too little attention to the research method and design. In the following sections the relevant research theory is interleaved with the application thereof to the re- 
search project described above (indicated by underlining). The scope of this paper excludes a detailed discussion of findings and implications but some are provided to serve as examples. For a full discussion of the findings and implications of this research see Ponelis (2011).

\section{Justification for Using Qualitative Case Studies}

Qualitative research produces holistic understandings of rich, contextual, and generally unstructured, non-numeric data (Mason, 2002) by engaging in conversations with the research participants in a natural setting (Creswell, 2009). The defining feature of case study research is its focus on 'how' and 'why' questions (Myers, 2009) and for this reason is appropriate for descriptive and exploratory studies (Mouton, 2001). A case study can focus on describing process(es), individual or group behavior in its total setting, and/or the sequence of events in which the behavior occurs (Stake, 2005).

The case method supports both theory building (Yin, 2009) and theory testing (Eisenhardt, 1989). The case study method's support for theory building is particularly useful in areas where existing theoretical and conceptual frameworks are inadequate (Chetty, 1996). Usually no hypothesis is formulated but "general ideas" or "expectations" can act as a guide to the empirical research (Mouton, 2001, p. 150). The insights arising from case-based theory building research can be used as hypotheses or propositions in further research. Case study research therefore plays an important role in advancing a field's body of knowledge (Merriam, 2009).

Answering the following four questions (Benbasat, Goldstein, \& Mead, 1987) can help to determine whether the case method is appropriate for a particular research situation:

1. Can the phenomenon of interest be studied outside its natural setting?

2. Must the study focus on contemporary events?

3. Is control or manipulation of subjects or events necessary [or possible]?

4. Does the phenomenon of interest enjoy an established theoretical base? (p. 372)

Although traditional hypo-deductive research has the widest applicability in IS research, a qualitative perspective provided by the use of, amongst others, case study research is also advanced (Galliers, 1992; Myers, 1997). By its nature exploratory research in emerging technologies in SMEs (1) cannot be studied outside of its natural setting, (2) focuses on contemporary events, (3) the control or manipulation of subjects, in this instance the owner/managers, and events is not possible, and (4) the theoretical knowledge on the phenomenon under investigation is limited and not yet mature. The case study method was thus a suitable method for my study. Furthermore, using case studies supports the relevance of my research since case studies are considered more persuasive to SME owner/managers than theoretical discussions (Levy \& Powell, 2005). Studies without a qualitative component cannot be used as a basis to recommend actions to owner/managers nor to inform policy (Merriam, 2009; Rozyn, 2007), a contribution that research into emerging technology use in SMEs often seeks to make.

The choice of research method reflects a particular epistemological stance and not just the "mere application of a specific data-gathering technique" (Perren \& Ram, 2004, p. 85). Qualitative research and case study research can be conducted within different research paradigms. The next section justifies using an interpretivist research paradigm.

\section{Justification for Working in the Interpretive Research Paradigm}

Positioning a research project within a paradigmatic framework is a worthwhile task that will lead researchers to "reflect upon the broader epistemological and philosophical consequences of their perspective" (Perren \& Ram, 2004, p. 95). Each research paradigm has certain assumptions, 
strategies, methods, and limitations, and the manner in which the quality of the resultant research is evaluated differs. A researcher must therefore choose the paradigm within which they will be working, understand the nature of their chosen paradigm, and document their paradigmatic choice in their writing (De Vos, Strydom, Fouché \& Delport, 2011, p. 41).

Interpretivism is based on a life-world ontology that argues all observation is both theory- and value-laden and investigation of the social world is not, and cannot be, the pursuit of a detached objective truth (Leitch, Hill, \& Harrison, 2010). Epistemologically, the viewpoint of the interpretivist paradigm is that our knowledge of reality is a social construction by human actors (Burrell $\&$ Morgan, 1979). The interpretive research paradigm is characterized by a need to understand the world as it is from a subjective point of view and seeks an explanation within the frame of reference of the participant rather than the objective observer of the action. At an axiological level, the interpretivist paradigm is more concerned with relevance than rigor.

The criteria used to evaluate the findings generated by research within the interpretive paradigm differ from those applied within the positivist paradigm (Lincoln \& Guba, 1985). While the value of the latter is judged by the degree to which results can be generalized to the wider population, the value of the understanding that emerges from an interpretive study is determined by the degree to which it fits and works with the perspectives of participants (Glaser \& Strauss, 1967). In positivist research the standards for judging research are reliability, validity, and generalizability. Some qualitative researchers are comfortable using the same terminology as in quantitative research whereas others prefer to use alternative terminology to better reflect the different nature of qualitative research. Dependability (reliability), credibility (validity), confirmability (objectivity), and transferability (generalizability) are used to establish the trustworthiness of qualitative research (Bloomberg \& Volpe, 2008).

Credibility refers to how well the researcher's portrayal of participants matches the participant's perceptions (Bloomberg \& Volpe, 2008). Dependability rests on the quality of the data collection and analysis (Lincoln \& Guba, 1985) and is shown by explaining that the research systematically studied what it claimed to study (Miles \& Huberman, 1994). Finally, transferability is about the degree to which the study has made it possible for the reader to apply the findings in the situations investigated to such other similar situations (Bloomberg \& Volpe, 2008; Lincoln \& Guba, 1985). It is also important to systematically report all evidence in order for the reader to confirm whether the findings flow from the data and experiences rather than from the bias and subjectivity of the researcher. Finally, transferability is about the degree to which the study has made it possible for the reader to apply the findings in the situations investigated to such other similar situations (Bloomberg \& Volpe, 2008; Lincoln \& Guba, 1985). Paying attention to trustworthiness criteria when planning, conducting, and documenting research is vital to convince readers and, in particular, examiners that the research is of a high quality (Oates, 2006).

The emerging nature of research in small enterprises is best suited to an interpretive qualitative approach that can yield a rich understanding of key issues by minimizing the distance between the researcher and the key SME decision-maker, the owner/manager, in order to develop the practical and theoretical understanding and generate new and alternative theories and concepts (Bygrave, 1989). From the perspective of IS research the dominant positivist approach has adversely affected the relevance of the resulting research (Lee, 1999). Researchers need to not only consider the technical aspects but also the social aspects and their continuing interaction with respect to the introduction and use of IS and IT in organizations (Lee, 2004), an approach to which interpretive research is ideally suited. When the researcher is interested in "the immediate response to a new innovation" such as an emerging technology it may require that researchers use subjective data "since it is unlikely that objective data would have been collected at precisely the right times or instances" (Smith, Gannon, \& Sapienza, 1989, p. 46). This is not to devalue positivist research but suggests that alternative approaches can supplement and strengthen SME research since quan- 
titative approaches cannot reveal the 'whole story' (Crotty, 1998). Further corroborating the chosen research approach for this project is the fact that other studies of emerging technology in SMEs used a similar research approach (Fink \& Disterer, 2006; Hill \& Scott, 2004). These publications do not, however, extensively motivate or document the justification for selecting their respective research designs and methods nor the research process.

Using qualitative interpretive case studies is thus justified for exploratory research. The following section documents the research design incorporating discussion of the trustworthiness criteria where applicable.

\section{Research Design}

A research design is the logic that links the research purpose and questions to the processes for empirical data collection, data analysis, in order to make conclusions drawn from the data (Bloomberg \& Volpe, 2008; Rowley, 2002; Yin, 2009). The research design implies or relies on the chosen research paradigm (Creswell, 2009). When using interpretive case studies for exploratory research key decisions for the researcher concern the role of prior theory, the unit(s) of analysis, the number and selection of cases, the techniques to be used for data collection, and the method(s) by which collected data will be analyzed (Eisenhardt, 1989). The sum of these decisions results in the case study protocol that helps to ensure uniformity in research projects where data is collected in multiple locations over an extended period of time (Maimbo \& Pervan, 2005). The following sections present the theoretical foundations for these key decisions together with the application to the author's research project.

\section{Outlining the role of prior theory}

Researchers attain theoretical sensitivity from a number of sources such as the literature and professional and personal experiences (Strauss \& Corbin, 1990). For new qualitative researchers working in areas where some understanding has already been achieved Miles and Huberman (1994) stress the importance of "prestructured research" (p. 17). The researcher, however, should try to purposefully limit taking any preconceptions arising from literature review into the field: no specific theories or propositions should be developed prior to meeting with participants. But as Eisenhardt (1989) concedes, it is impossible for researchers to start with a clean theoretical slate, and it is "impossible to embark upon research without some idea of what one is looking for" (Wolcott, 1994, p. 157). Exploratory case studies do not start with propositions developed from a prior review of literature; rather the analytic strategy is to develop a descriptive framework for organizing the case studies (Rowley, 2002) in order to direct the exploratory empirical study (Hartley, 1994).

In my research project I explored the emerging literature on BI and the wider literature on SMEs in order to generate the problem statement and purpose that would contribute to extant knowledge, frame the research, and develop a descriptive framework. As a result of the lack of a single widely accepted definition of BI, I first defined BI using qualitative content analysis of a selection of definitions of BI by academics, practitioners, and software vendors, the result of which I used as a descriptive framework to direct the empirical research (Ponelis \& Britz, 2012).

\section{Deciding on the unit of analysis}

The unit of analysis is the basis of each case. The unit of analysis may be an individual such as a person who has had an experience of interest to the study, an event such as a decision, a social process, an implementation process, an organization or part thereof (Myers, 2009; Rowley, 2002). As central decision-maker the owner/manager's "strategic position serves as 'focal' point, around which all business activities are centralized, including those of information search and assimilation" (Lybaert, 1998, p. 188). My research focused on a process in an organization, the use of 
information for decision-making in the SME, by the person involved, the owner/manager as the predominant decision-maker. Therefore, the unit of analysis in my research project was a combination of the SME and the owner/manager with the emphasis on the owner/manager as the key decision-maker and thus consumer of information for decision-making in the SME.

\section{Selecting the cases}

Eisenhardt (1989) states that the "random selection of cases is neither necessary, not even preferable" (p. 537) and relevance to the research questions rather than representativeness is the criterion the selection of cases (Carson, Gilmore, Perry, \& Gronhaug, 2001). The underlying principle in selecting appropriate cases is the preference for cases that are information-rich with respect to the topics under investigation, and therefore using purposive sampling as well as snowball sampling is justified (Patton, 2002). With owner/managers as a unit of analysis, access to at least one of the owner/managers was an important consideration in the selection of cases. Following the advice of Hartley (1994) that contacts in industry, academia, and friendship can be helpful to establish a list from which cases can be selected, an approach also used by Chibelushi and Costello (2009), potential cases were obtained using a snowball sampling strategy using:

- personal networks and word-of-mouth referrals; and

- businesses located in a science park associated with the university.

\section{Deciding the number of cases}

In interpretive research the number of participants is relatively small (Holloway, 1997). Y in (2009) highly recommends that novice researchers begin "with a simple and straightforward case study" (p. 162) because of the complexity of managing and analyzing the large volumes of data. However, evidence from multiple cases is "often considered more compelling, and the overall study is therefore regarded as being more robust" (Yin, 2009, p. 53) and provides a valid basis for understanding (Levy \& Powell, 2005). Although there is no ideal number of cases, there are several recommendations:

- Eisenhardt (1989, p. 545) believes that between four and ten cases often works well.

- Crabtree and Miller (1992) advocate a sample size of six to eight subjects for homogenous samples.

- Curran and Blackburn (2001) indicate that case studies in small business research are often fewer than ten.

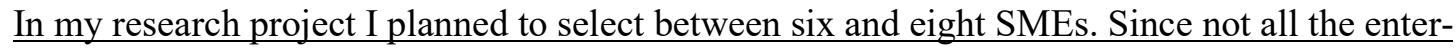
prises contacted for inclusion might have agreed to participate in the research or proved to be suitable cases, thirteen SMEs were initially contacted. The initial request for participation was sent by e-mail to owner/managers of the firms and included a brief overview of the purpose of the research, the reason why their participation is important, and the involvement that would be required if they chose to participate. Four firms did not respond, of those that did two did not meet the selection criteria.

\section{Determining the data collection technique(s) and procedures}

One of the strengths of the case study method is its flexibility and adaptability that allows single or multiple methods of data collection to be used to investigate a research problem (Cavaye, 1996). A wide variety of data collection methods can be used including direct observation, participant observation, interviews, focus groups, documentary sources, archival records, and physical artifacts (Mouton, 2001, Myers, 2009). Using multiple sources of data - and multiple participants 
(Maimbo \& Pervan, 2005) - is preferable in order to triangulate data (Yin, 2009) and to allow significant insights to emerge (Myers, 1997).

Whilst interpretivist research often relies on total immersion in a setting this is not necessarily a requirement. A primary source of data in both qualitative research (Easterby-Smith, Thorpe, \& Lowe 1991; Myers \& Newman, 2007) and in case studies (Yin, 2009, p. 106) is the interview. Secondary data can be collected from various sources depending on the research focus, for example, annual reports and financial statements, public records, newspapers and social media (Maimbo \& Pervan, 2005), organization charts, and minutes of meetings (Myers, 2009). It is important to keep in mind that interviewing does not, however, automatically guarantee the collection of rich data and production of meaningful insights (Schulze \& Avital, 2011).

In my research project the objectives of data collection were to understand how the participant became a SME owner together with the subsequent developmental history of the business, and to obtain insight into the use of information and BI for decision-making by the owner/manager in the SME. I opted for semi-structured interviews to keep the interviews focused and facilitate cross-case analysis (Carson et al, 2001) but also to provide room to explore new and relevant issues that emerge during the interview. The interview guide was designed to capture the context, content, and process with regard to the use of information and role of BI in decision-making in the selected SMEs (included as an appendix in my dissertation). Background information on the enterprises was gathered through sources in the public domain, for example, company websites and the government's companies register. Background information on owner/managers was also gathered from the public domain using public profiles on professional networks (LinkedIn) and media monitoring.

\section{Collecting, analyzing and interpreting data}

When analyzing data, the qualitative researcher attempts to make sense and interpret the phenomena in terms of the meaning the participants place on them (Creswell, 2009). A variety of qualitative data analysis methods such as content analysis, constant comparison and pattern matching can be used. Whichever approach is chosen qualitative researchers should make the process involved in their collection and analysis of data as explicit as possible. Researchers employing qualitative methods that fail to do so "do little to encourage theory development or progress current knowledge and understanding" (Shaw, 1999).

The qualitative interview data were analyzed using Cope's (2005) four levels of analysis (Levels 1 through 4) with an additional level that considers the data collection and recording process itself as the first level of analysis (Level 0 ) as is discussed explicitly below. (Note that data collection and analysis is an iterative process and that the researcher iterates between the different levels of analysis throughout the data collection process even though it is discussed consecutively.)

\section{Level 0: Conducting interviews}

The process of inductively analyzing data commences as soon as the researcher starts collecting data, that is, during the interviews (Shaw, 1999). For this reason, whenever possible, the researcher(s) should conduct all interviews. Alvesson (2003), furthermore, encourages researchers to consider the impact of the social setting in which the interview takes place (e.g., interviewer's background, experience, gender, age, and nationality), the physical setting, and the impact of language use on the interview, for example, use of terminology with which the interviewee is unfamiliar.

The face-to-face interviews were conducted over a four-week period. Each interview lasted about one hour and was conducted face-to-face to establish rapport, build trust, and to identify any nonverbal cues that warranted further questioning. Five of the seven interviews were conducted in Afrikaans, one of the official languages in South Africa, based on the preference of the interview- 
ees. All the interviewees were male. Interviews were conducted at the participants' place of work, normally a quiet office, except in two instances where participants with home offices requested that interviews be conducted in coffee shops.

Prior to starting the interview most of the participants were interested to know why they had been chosen to participate in the research. The first 5 to 10 minutes of the interview was spent discussing my background, the reasons for conducting the research, and what I hoped to achieve. This discussion allowed me to explain the purpose of the study and to discuss informed consent including confidentiality, anonymity, voluntary participation, the option to withdraw at any point and details on the university's approval of my research (the cover letter and informed consent form given to participants are included as appendices in my dissertation). At this point I also requested permission to record the conversation for transcription, that an account of the interview will be provided to verify accuracy and that notes will be taken (notes were taken as back-up in case of equipment failure where audio recordings were permitted).

\section{Level 1: Transcribing and capturing of notes}

Level 1 analysis comprises the reading of each transcript and set of notes several times with the researcher making detailed notes to highlight potentially significant issues and experiences (Patton, 2002). This serves to familiarize the researcher with the data (Easterby-Smith et al, 1991) and to begin the process of organizing and structuring the data and increases the researcher's awareness of the patterns, themes, and categories in the data. I reviewed all my notes immediately after each interview and in the case of interviews without audio recording added additional notes for clarity and detail. I transcribed the interviews in the same order that they were conducted (Peräkylä, 1997) as soon as I returned from fieldwork in South Africa to the USA using a denaturalistic transcription style where "idiosyncratic elements of speech (e.g., stutters, pauses, nonverbal, involuntary vocalizations) are removed" (Oliver, Serovich \& Mason, 2005, pp. 1273-1274).

\section{Level 2: Writing up case study narratives and within-case analysis}

During Level 2 analysis the transcripts and notes are developed into coherent and manageable yet rich write-ups for each case structured according to the descriptive framework in order to allow subsequent cross-case analysis. Rich descriptions in the form of case narratives allow the reader to judge the transferability of the interpretation and also the results, thereby also increasing dependability. Case studies can be presented chronologically, thematically, or both. In my research project the case study narrative was both thematic and chronological because the narrative explains the use of data, systems, and information in relation to decision-making within the context of the owner/mangers' and the SMEs' development over time. The following are the primary headings that were established as the key focal points for case narratives based on the interview guide:

1. Introduction and general background of the SME;

2. Owner/manager profile; and

3. Use of information and BI in the SME.

This resulting summary of the interview should be shared with participants for confirmation that the narrative the researcher captured is consistent with what participants believe they had shared during their interviews and to eliminate any misunderstandings on the part of the researcher. Such confirmation also adds to the credibility of the research (Creswell, 2009). I shared the case narratives with the participants and asked that if there were any inaccuracies, misunderstanding, or content they were unhappy with for any reason that they please let me within two weeks after which I would assume that they were in agreement with the write-up of our interview. 


\section{Level 3: Determining findings through cross-case analysis}

The third level of analysis is concerned with cross-case comparisons to seek out what is common and what is particular in the cases (Stake, 2005). This level of analysis can result in a unified description across cases, categories, themes, or typologies that conceptualize the data across all the cases, or in building a substantive theory that offers an integrated framework covering multiple cases (Merriam, 2009).

A frequently used method of cross-case analysis is qualitative content analysis. Qualitative content analysis involves identifying coherent and important themes and patterns in the data: the researcher looks for "quotations or observations that go together, that are examples of the same underlying idea, issue, or concept" (Patton, 1987, p. 149). The themes and categories are constructed through coding, and researchers can choose from a variety of approaches. Two main approaches are an emergent approach, which is the more conventional grounded theory approach, or an a priori directed approach. In emergent coding no prior themes are established and themes emerge through repetitive scrutiny and comparison of the data. With a priori coding themes are established prior to the analysis based upon literature and the themes are then applied to the collected data. The outcome of this level of analysis is the findings based on the collected data.

An a priori approach was used with themes established prior to the analysis based upon descriptors in my descriptive framework of BI. Key findings from the cross-case analysis were, not surprisingly, that information derived from internally and externally sourced data plays an important role for owner/managers in managing their enterprises. Almost all would like to see improved access to existing data sources and/or access to additional data sources. Assistance from external parties that they already have relationships with and trust is sometimes required to assist with data analysis but owner/managers would prefer to do this independently and on a more regular basis. These trusted parties are predominantly accounting and tax professionals and personal bankers. IT is seen as a means to achieve business objectives and not an end in itself. Inexpensive, flexible solutions that are easy to implement and use are preferred, predominantly open source web-based applications. However, owner/managers feel that they do not have sufficient time to explore available solutions and, once decided upon, have limited in-house IT skills to implement the preferred solutions.

\section{Level 4: Interpreting and enfolding findings in literature}

In order to develop a deeper understanding of the data collected Level 3 analysis involves the "clustering" together of findings (Hycner, 1985) without the use of any relevant theoretical literature. In Level 4 the findings are discussed in the context of extant literature, a process that Eisenhardt (1989) calls enfolding literature, and the outcome of this level of analysis is the interpretation of the findings.

Comparing the findings from Level 3 to what has been reported in the extant literature several issues reported in the literature were confirmed to also apply to the selected South African SMEs. For example, the finding on trusted third parties confirmed the SME Survey (2008) that found business owners look to their accountants $(72 \%)$ or financial institutions $(59 \%)$ for business expertise with comparatively few who make use of business consultants $(33 \%)$ and mentoring or coaching $(9 \%)$. However, findings also contradicted some issues reported in literature. For example, in contrast to earlier studies (Cragg \& King, 1993; Fink, 1998) this study revealed a preference amongst SMEs of all sizes for the more recently available, open source web-based applications over in-house packaged software.

\section{Concluding and writing up of the case study report}

The most common method of writing up case studies is to use a convincing story (Yin, 2009) that relies on rich pictures created by the descriptive narrative. The final write-up or case report may 
have a greater proportion of description than other forms of qualitative research in order to convey a holistic understanding of the case (Merriam, 2009) but the ultimately the extent of description, analysis, or summary material included is up to the researcher. According to Stake (2005) the case study researcher must decide:

1. How much to make the report a story;

2. How much to compare with other cases;

3. How much to formalize generalizations or leave such generalizing to readers;

4. How much description of the researcher to include in the report; and

5. Whether or not and how much to protect anonymity (p. 460).

The decisions made in answer to the above questions will differ for each study depending on the nature of the research question. It is important to keep in mind that findings are considered dependable if, among others, the researcher's subjective role is outlined and the researcher explained the data collection and recording process in detail (Gorman \& Clayton, 2005). Walsham (1993) contends that the validity of extrapolation from cases depends on "the plausibility and cogency of the logical reasoning used in describing the results from the cases, and in drawing conclusions from them" (p. 15). Qualitative research can conclude with either recommendations or implications. Although recommendations are far more direct, the limitations of qualitative interpretive research with regard to generalizability make recommendations hazardous, and it is therefore preferable to present the implications of the research results (Wolcott, 1990).

In my dissertation I opted to present the case narratives from the Level 1 of analysis as stories, compared cases in as much detail as possible in Level 2 of analysis, formalized my cross-case analysis findings in Level 3 of analysis, compared findings to extant literature in Level 4 of analysis, included a description of myself (background, interview experience, prior knowledge) and protected anonymity by, amongst others, assigning letter numbers to cases, changing names and omitting identifying details to the fullest extent possible without sacrificing a rich description.

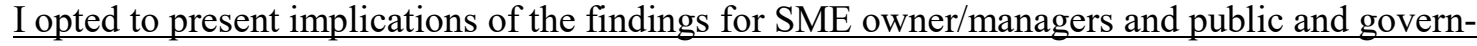
ment support agencies, business advisers, BI vendors and practitioners and other stakeholders rather than recommendations. Apart from directly contacting owner/managers, trusted third parties can serve as a secondary channel through which potential BI solutions and service providers can be communicated to owner/managers. Owner/managers also need to assess whether time spent waiting for external parties to gather, integrate, and manipulate data for decision-making is worthwhile versus the time and money spent on assessing, adopting, and using suitable IT solutions to meet their information needs themselves.

\section{Lessons Learned and Recommendations}

Because of its wide applicability and strengths the case study method is a popular research method but it must be selected with caution. As Myers (2009) states, it is "a serious mistake to think that case study research is an easy or a soft option" (p. 82).

Myers (2009) warns that it can be difficult to gain access to the target population, and this was also my experience. As Hill and Wright (2000) rightly state, access to suitable enterprises can be difficult and beset with all sorts of problems. Research into the impact of technology on SMEs is often limited by the difficulties involved in persuading the right enterprises to participate in the study (Jeffcoate, Chappell \& Feindt, 2002), who are expected to give up their valuable time without understanding the value that the research has to them (Myers, 2009). Do not underestimate the difficulty of finding enough suitable and willing cases to study. Personal networks were vital to identify suitable SMEs and obtain commitment to participate in my study. If you - or your su- 
pervisor(s) - do not have personal networks that can be leveraged to facilitate access it may be a greater challenge and more time-consuming than you initially expected.

Given that personal networks were used to identify cases, two of the seven owner/managers knew me personally. These participants in particular may have had difficulty adjusting to me in the role of interviewer, and their responses may have been influenced or affected as a result, on top of the to be expected participant reactivity. But as Myers and Newman (2007) state, "the more comfortable interviewees are, and the more they are prepared to open up and talk, the better the disclosure is likely to be" (p. 15). Given that the adoption and use of emerging technologies can have strategic importance and impact competitive advantage, owner/managers may understandably be reluctant to share such confidential information with a stranger. Trust is important to promote truthful sharing, and therefore I assumed that any influence of prior relationships had a greater positive rather than negative effect on the quality of data gathered in these instances. What I initially considered to be a limitation turned out to have a beneficial effect.

The flexibility of semi-structured interviews proved to be valuable, not just to provide the possibility to explore issues that emerged during the interviews but also to adjust the questions to the participants' level of knowledge of the issue. Interviewees may lack the correct terms for concepts they are using but this does not imply a lack of understanding or application of the concepts. Although all the respondents were asked about the same themes, I was able to adapt the formulation of the probe questions, including the terminology, to fit the background and educational level of the participants and thus adjust the questions according to the language the participants used. This served to improve the quality of the data gathered and enhanced the dependability and credibility of the study. Furthermore, the semi-structured approach also promoted the conversational nature of the interview and rapport with the interviewer.

The data collection process is critically dependent upon the competence of the researcher, which implies that the interviewer needs to be able to ask well-structured and relevant questions, be able to listen and interpret the answers (Rowley, 2002), and find a balance between passivity and overdirection (Walsham, 1995). Experience in interviewing improves the quality of the data collected and consequently, the results of the research. If you are an inexperienced interviewer consider role-playing with a more experienced mentor prior to interviewing participants. It must be noted, as Walsham (1995) remarks, that good interviewing technique is necessary but not sufficient for "good interviewing," which requires "good social skills and personal sensitivity on the part of the researcher, and these are less easily acquired than matters of technique" (p. 78).

In spite of your best efforts during case selection, cases may still not meet your criteria. After conducting the interview I had to omit one of the cases from further levels of analysis because the owner/manager did not share sufficient information. Identify and obtain commitment from more cases than you minimally need to avoid scrambling to find sufficient cases at the last minute, particularly if your data collection involves traveling to a different geographic location that cannot be revisited without considerable expense.

During case study research large volumes of data are collected from multiple sources. One of the challenges, particularly in a multi-case study is the management of the collected data. The researcher must find ways to manage the data without being overwhelmed. It is important to store collected data comprehensively and systematically so that it can be analyzed and referenced (Pickard, 2013). It is vitally important to structure data as early as possible, ideally as soon as data collection commences. Software packages such as NVivo can assist with data management as well as analysis but the software cannot discover themes, it remains the responsibility of the researcher. I elected not to use software to support my analysis since it can be time consuming to master and use. Given the effort to link data to themes there is also a risk of getting 'locked in' to themes as a result (Walsham, 2006, p. 325). I used word processing and spreadsheet packages to support 
my analysis and organized my case 'database' by means of files in folders. My approach worked well for the volume of data that I gathered and analyzed but if you do have access and time it is an ideal opportunity to learn how to use such software, particularly if you plan on using large volumes of data.

Overall, gaining access, collecting and analyzing data, and, finally, writing up was a much more time-consuming process than I expected, as Mouton (2001) rightly warns. Be sure to build in buffers in your plan.

Apart from the valuable networking and exposure to presenting research results at conferences, subjecting the research process and results to peer review at academic conferences functions as a form of peer debriefing after the data analysis and interpretations have been made (Given, 2008). This is particularly useful for qualitative research. I presented initial results at a regional conference (Ponelis \& Britz, 2011a) and final results at a workshop at a national conference (Ponelis \& Britz, 2011b). It was highly beneficial to receive feedback from reviewers and audience members to improve the overall quality of the research.

Readers and, in particular, examiners will rely on the method chapter to understand how you arrived at your conclusions and determine the trustworthiness (or validity for positivist research) of the evidence upon which you base your discussion, interpretation, conclusion, and recommendations/implications. As Hofstee (2006) states, "The first place to look for weaknesses in a work is in the method chapter" (p. 110). Therefore, it is critical to choose an appropriate method to answer your research questions or achieve the stated purpose, to fully describe and justify the choice in the dissertation's methods chapter, and to fully describe and validate the data collection method and process (Hofstee, 2006). As you review the literature be sure to pay attention not just to the research questions and the results but also the method used to arrive at the results. It will be very useful if you cite other studies with similar research questions or problems to yours that used a similar approach as motivation for your chosen approach. Reviewing the research approaches as part of your literature review saves you time in the long run. Note that you should also review and reference literature specifically on methodology. (Alternatively, if you see that all or most research reported in the literature uses a similar research approach this can be an opportunity for you to investigate the problem using a different research approach and make a methodological contribution to the field.) I opted to work within the interpretive paradigm rather than the dominant positivist paradigm in IS. It was not, however, a novel contribution; prior SME research had already been conducted within this paradigm and I cited these studies to justify my research approach.

Finally, published research, methodology texts, and dissertations create the impression that research is a linear process but this is not what happens in practice. As Ulibarri, Cravens, Cornelius, Royalty, and Nabergoj (2014) state, "Scholarly research happens in a messy, nonlinear process." Do not be discouraged if your research takes unexpected twists and turns.

\section{Conclusion}

The use of the case research method has gained mainstream acceptance as a research method that can be used to develop propositions, conceptual models, and theory that are novel, yet grounded in the literature in many fields including entrepreneurship and information systems. Using interpretive qualitative case studies enabled the researcher to build descriptions of the context within which case-enterprises used an emerging technology and provided the flexibility to uncover and explore issues that emerged as interesting and potentially relevant to the research problem during data collection. In the doctoral research study considerable amount of time was devoted to the method because it is the foundation for trustworthy research, particularly in the case of qualitative research. The example presented in this paper is itself a single case study of the methodological 
decisions for a doctoral research project. By presenting as much relevant detail in as succinct a manner as possible the hope is that there is sufficient transferability for current and future doctoral students to benefit from this example in their research endeavors.

\section{References}

Alvesson, M. (2003). Beyond neopositivists, romantics, and localists: A reflexive approach to interviews in organizational research. Academy of Management Review, 28(1), 3-33.

Barnes, D. J., Buckland, B. K., \& Brancheau J. C. (1992). Methodological issues in emerging technologies research: Experiences and recommendations. Proceedings of the Twenty-Fifth Hawaii International Conference on System Sciences, 4, 325-336.

Benbasat, I., Goldstein, D. K., \& Mead, M. (1987). The case research strategy in studies of information systems. MIS Quarterly, 11(3), 369-385.

Bloomberg, L. D., \& Volpe, M. (2008). Completing your qualitative dissertation: A roadmap from beginning to end. Thousand Oaks, CA: Sage.

Burrell, G., \& Morgan, G. (1979). Sociological paradigms and organisational analysis: Elements of the sociology of corporate life. London: Heinemann.

Bygrave, W. D. (1989). The entrepreneurship paradigm (I): A philosophical look at its research methodologies. Entrepreneurship Theory and Practice, 14(1), 7-26.

Carson, D., Gilmore, A., Perry, C., \& Gronhaug, K. (2001). Qualitative marketing research. London: SAGE Publications.

Cavaye, A. L. M. (1996). Case Study Research: A Multi-Faceted Research Approach For IS. Information Systems Journal, 6(3), 227-242.

Chetty, S. (1996). The case study method for research in small- and medium-sized firms. International Small Business Journal, 15(1), 73-85.

Chibelushi, C., \& Costello, P. (2009). Challenges facing W. Midlands ICT-oriented SMEs. Journal of Small Business and Enterprise Development, 16(2), 210-239.

Cope, J. (2005). Researching entrepreneurship through phenomenological inquiry philosophical and methodological issues. International Small Business Journal, 23(2), 163-189.

Crabtree, F. B., \& Miller, L.W. (1992). Doing qualitative research. Beverly Hills, CA: Sage.

Cragg, P. B., \& King, M. (1992). Information system sophistication and financial performance of small engineering firms. European Journal of Information Systems, 1(6), 417-426.

Creswell, J. W. (2009). Research design: Qualitative, quantitative, and mixed methods approaches. Thousand Oaks, Calif.: Sage.

Crotty, M. J. (1998). The foundations of social research: Meaning and perspective in the research process. London: Sage.

Curran, J., \& Blackburn, R.A. (2001). Researching the small enterprise. London: Sage.

Davies, M. R. (2007). Doing a successful research project: Using qualitative or quantitative methods. Basingstoke, UK: Palgrave Macmillian.

De Vos, A. S., Strydom, H., Fouche, C. B., \& Delport, C. S. L. (2011). Research at grass roots: For the social sciences and human service professions (4th ed.). Pretoria, South Africa: Van Schaik.

Easterby-Smith, M., Thorpe, R., \& Lowe, A. (1991). Management research: An introduction. London, UK: Sage.

Eisenhardt, K. M. (1989). Building theories from case study research. Academy of Management Review, 14(4), 532:550. 
Fink, D. (1998). Guidelines for the successful adoption of information technology in small and medium enterprises. International Journal of Information Management, 18(4), 243-253.

Fink, D., \& Disterer, G. (2006). International case studies: To what extent is ICT infused into the operations of SMEs? Journal of Enterprise Information Management, 19(6), 608-624.

Galliers, R. D. (1992). Information systems research: Issues, methods and practical guidelines. Oxford, UK: Blackwell.

Given, L. M. (Ed.). (2008). The Sage encyclopedia of qualitative research methods. Thousand Oaks, CA: Sage Publications, Inc.

Glaser, B., \& Strauss, A. (1967). The discovery of grounded theory. Chicago, IL: Aldine.

Gorman, G., \& Clayton, P. (2005). Qualitative research for the information professional: A practical handbook. London, UK: Facet.

Hartley, J. F. (1994). Case studies in organisational research. In C. Cassell \& G. Symon (Eds.), Qualitative methods in organisational research (pp. 208-229). London: Sage.

Hill, J., \& Scott, T. (2004). A consideration of the roles of business intelligence and e-business in management and marketing decision making in knowledge-based and high-tech start-ups. Qualitative Market Research: An International Journal, 7(1), 48-57.

Hill, J., \& Wright, L. T. (2000). Defining the scope of entrepreneurial marketing: A qualitative approach. Journal of Enterprising Culture, 8(1), 23-46.

Hofstee, E. (2006). Constructing a good dissertation: A practical guide to finishing a Master's, MBA or $P h D$ on schedule. Sandton, South Africa: EPE.

Holloway, I. (1997). Basic concepts for qualitative research. Oxford, UK: Blackwell Science.

Hycner, R. H. (1985). Some guidelines for the phenomenological analysis of interview data. Human Studies, 8(3), 279-303.

Jeffcoate, J., Chappell, C., \& Feindt, S. (2002). Best practice in SME adoption of e-commerce. Benchmarking: An International Journal, 9(2), 122-132.

Lee, A. S. (1999). Rigor and relevance in MIS research: Beyond the approach of positivism alone. MIS Quarterly, 23(1), 29-34.

Lee, A. S. (2004). Thinking about social theory and philosophy for information systems. In L. Willcocks \& J. Mingers (Eds.), Social theory and philosophy for information systems (pp. 1-26). Chichester, UK: John Wiley \& Sons.

Leitch, C. M., Hill, F. M., \& Harrison, R. T. (2010). The philosophy and practice of interpretivist research in entrepreneurship: Quality, validation, and trust. Organizational Research Methods, 13(1), 67-84.

Levy, M., \& Powell, P. (2005). Strategies for growth in SMEs: The role of information and information systems. Elsevier Butterworth-Heinemann Information Systems Series. Oxford: Elsevier ButterworthHeinemann.

Lincoln, Y. S., \& Guba, E. G. (1985). Naturalistic inquiry. Beverly Hills, CA: Sage.

Lybaert, N. (1998). The information use in a SME: Its importance and some elements of influence. Small Business Economics, 10(2), 171-191.

Maguire, S., Koh, S., \& Magrys, A. (2007). The adoption of e-business and knowledge management in SMEs. Benchmarking: An International Journal, 14(1), 37-58.

Maimbo, H., \& Pervan, G. (2005). Designing a case study protocol for application in IS research. Proceedings of the Ninth Pacific Asia Conference on Information Systems (PACIS 2005), Bangkok, Thailand, July 7-10, 2005, pp. 1281-1292.

Mason, J. (2002). Qualitative researching (2nd ed.). London: Sage. 
Merriam, S. B. (2009). Qualitative research: A guide to design and implementation (2nd ed.). San Francisco, CA: Jossey-Bass.

Miles, M. B., \& Huberman, A. M. (1994). Qualitative data analysis: An expanded sourcebook (2nd ed.). Thousand Oaks, CA: Sage.

Mouton, J. (2001). How to succeed in your Master's and Doctoral Studies: A South African guide and resource book. Pretoria: Van Schaick Publishers.

Myers, M. (1997). Interpretive research in IS. In J. Mingers \& F. Stowell (Eds.), Information systems: An emerging discipline (pp. 239-266). Maidenhead: McGraw-Hill.

Myers, M. D. (2009). Qualitative research in business and management. London, UK: Sage.

Myers, M. D., \& Newman, M. (2007). The qualitative interview in IS research: Examining the craft. Information and Organization, 17(1), 2-26.

Oates, B. J. (2006). Researching information systems and computing. London: Sage.

Oliver, D. G., Serovich, J. M., \& Mason, T. L. (2005). Constraints and opportunities with interview transcription towards reflection in qualitative research. Social Forces, 84(2), 1273-1289

Patton, M. Q. (1987). How to use qualitative methods in evaluative research. London: Sage.

Patton, M. Q. (2002). Qualitative evaluation and research methods (3rd ed.). Newbury Park, Calif.: Sage.

Peräkylä, A. (1997). Reliability and validity in research based on tapes and transcripts. In D. Silverman (Ed.), Qualitative research: Theory, method and practice (2nd ed.) (pp. 283-304). London: Sage.

Perren, L., \& Ram, M. (2004). Case-study method in small business and entrepreneurial research: Mapping boundaries and perspectives. International Small Business Journal, 22(1), 83-101.

Pickard, A. J. (2013). Research methods in information (2nd ed.). Chicago, IL: Neal-Schuman.

Ponelis, S. R. (2011). An exploratory study of business intelligence in knowledge-based growth small, medium and micro- enterprises in South Africa. (Doctoral dissertation, University of Pretoria). Retrieved November 3, 2015 from http://upetd.up.ac.za/thesis/available/etd-02102012-152957/

Ponelis, S. R., \& Britz, J. J. (2011a, May 20-21). The role of business intelligence in information-intensive small businesses: Initial results from an interpretive study. MWAIS 2011 Proceedings, Paper 23. Nebraska, Omaha, USA. Retrieved November 5, 2015 from http://aisel.aisnet.org/mwais2011/23

Ponelis, S. R., \& Britz, J. J. (2011b, August 4). An exploratory study of business intelligence in knowledgebased South African SMEs. GlobDev 2011 Pre-AMCIS Workshop: ICT in Global Development, Paper 201, Detroit, Michigan, USA. Retrieved November 5, 2015 from www.globdev.org/files/AMCIS\%20Proceedings\%202011/Paper\%201.pdf

Ponelis, S. R., \& Britz, J. J. (2012). A descriptive framework of business intelligence derived from definitions by academics, practitioners and vendors. Mousaion, 30(1), 103-119.

Rowley, J. (2002). Using case studies in research. Management Research News, 25(1), 16-27.

Rozyn, S. (2007). The key success factors in growing a small and medium enterprise (SME) in South Afri$\mathrm{ca}$. (MBA dissertation, Gordon Institute of Business Science, University of Pretoria). Retrieved November 3, 2015 from http://upetd.up.ac.za/thesis/available/etd-03252010-161953/.

Schulze, U., \& Avital, M. (2011). Designing interviews to generate rich data for information systems research. Information and Organization, 21(1), 1-16.

Sen, B. A., \& Taylor, R. (2007). Determining the information needs of small and medium-sized enterprises: A critical success factor analysis. Information Research, 12(4), paper 329. Retrieved November 3, 2015 from http://informationr.net/ir/12-4/paper329.html

Shaw, E. (1999). A guide to the qualitative research process: Evidence from a small firm study. Qualitative Market Research: An International Journal, 2(2), 59-70. 
SME Survey. (2008, June 22-25). The blueprint for a successful SME in South Africa. Paper presented at 2008 International Council for Small Business World Conference, Halifax, Nova Scotia, Canada.

Smith, K. G., Gannon, M. J., \& Sapienza, H. J. (1989). Selecting methodologies for entrepreneurial research: Trade-offs and guidelines. Entrepreneurship Theory and Practice, 14(1), 39-49.

Stake, R. E. (2005). Qualitative case studies. In N. K. Denzin \& Y. S. Lincoln (Eds.), The Sage handbook of qualitative research (3rd ed.) (pp. 443-466). Thousand Oaks, CA: Sage.

Strauss, A., \& Corbin, J. (1990). Basics of qualitative research: Grounded theory procedures and techniques. Thousand Oaks, CA: Sage.

Ulibarri, N., Cravens, A. E., Cornelius, M., Royalty, A., \& Nabergoj, A. S. (2014). Research as design: Developing creative confidence in doctoral students through design thinking. International Journal of Doctoral Studies, 9, 249-270. Retrieved from http:/ijds.org/Volume9/IJDSv9p249270Ulibarri0676.pdf

Walsham, G. (1993). Interpreting information systems in organizations. Chichester, UK: Wiley.

Walsham, G. (1995). Interpretive case studies in IS research: Nature and method. European Journal of Information Systems, 4(2), 74-81.

Walsham, G. (2006). Doing interpretive research. European Journal of Information Systems, 15(3), 320330 .

Wolcott, H. F. (1990). Writing up qualitative research. Qualitative Research Methods Volume 20. Thousand Oaks, CA: Sage.

Wolcott, H. F. (1994). Transforming qualitative data: Description, analysis and interpretation. Thousand Oaks, CA: Sage.

Yin, R. K. (2009). Case study research: Design and methods (4th ed.). Thousand Oaks, Calif.: Sage.

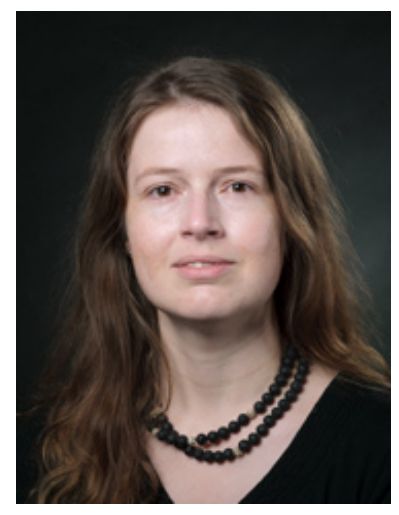

\section{Biography}

Shana R. Ponelis is an Assistant Professor in the School of Information Studies at the University of Wisconsin-Milwaukee (UWM) and a Research Associate of the Department of Information Science at the University of Zululand in South Africa. Before joining UWM she was a Senior Lecturer with the Department of Informatics at the University of Pretoria (UP). Her research purpose is the empowerment of people to enable them to make informed decisions to develop themselves, their organizations, their communities and society as a whole. She also actively engages and contributes to the scholarship of teaching and learning (SoTL).

Her work has been published in, amongst others, Aslib Proceedings, Information Development, Journal of Information Ethics, South African Journal of Information Management and The International Information \& Library Review. She has presented papers and led panel discussions at various regional, national and international conferences such as MWAIS, $I A C I S$ and Conf-IRM and has co-chaired SIG GlobDev mini-tracks at AMCIS since 2012. She teaches various courses on ICT in undergraduate and graduate programs at UWM and UP in faceto-face, online and flexible modes of delivery. Shana also supervises several Masters and doctoral students enrolled at universities in Africa. She holds a PhD in Information Technology from the University of Pretoria, South Africa. 